\title{
Analysis of Secondary Grade Mathematics Question Papers of Boards of Intermediate and Secondary Education in Punjab
}

\author{
Muhammad Saeed ${ }^{*}$ \\ Afshan Naseem $^{* *}$
}

\begin{abstract}
The purpose of this study was to investigate the quality of mathematics question papers of Boards of Intermediate and Secondary Education (BISE) for grade 9 and 10 (secondary level) as per national curriculum 2006. The BISE question papers in the subject of mathematics of grade IX-X for the two academic years 2012 and 2013 were analyzed in terms of the weightage of different cognitive abilities suggested in the national curriculum. The analysis was made on the basis of the basic principles of test item construction found in literature and the weightage of various cognitive abilities narrated in national curriculum. It was found that question papers were largely assessing students' lower cognitive abilities (knowledge and comprehension); a few items were assessing higher cognitive abilities (application and analysis). Since the cognitive abilities of synthesis and evaluation were not desired to assess in the national curriculum (2006) of mathematics, so these were ignored. Some of the questions were weak in terms of language and format/style. The study suggests that teachers should be aware of the national curriculum document with special reference to assessment and BISE should organize intensive training for teachers in test item construction, especially those involved in developing mathematics question papers for BISE.
\end{abstract}

Keywords: Assessment Scheme, Bloom's Taxonomy of Educational Objectives, Mathematics Question Papers, Secondary Education

Associate Professor, Institute of Education and Research, University of the Punjab, Lahore

** PhD Scholar, institute of Education and Research, University of the Punjab, Lahore 


\section{Introduction}

Education in its general sense is considered a form of learning in which knowledge, skills and traits of a group of people are transferred from one generation to the next and this transformation takes place through teaching, training and research. Any practice or experience that influenced the way one thinks, feels, or acts may be considered educational. There are different stages in which education is commonly divided such as preschool, elementary school, secondary school, college and university. Education is a continuous process of human and economic development which is inclined by the surroundings where human beings live. These surroundings affect the policies i.e. changing trend in technology, labour and market patterns or environment of the globe. Cultural and traditional beliefs have an effect on our educational system as well as have an effect by each other. The element of change is continued but guided by the society from which it emerges (National Education Policy, 2009).

The Government of Pakistan and Government of the Punjab are committed to improve the quality of education along with its efforts to increase enrolment and access. Policy document by Government is the reflection of this commitment and its credibility is determined by international forum and students' scores in exams are indicators to regulate its credibility in the educational zone. One of the fundamental advantages of assessment in school environment at federal and provincial level is that it measures the learning outcome in a better way and contributes to increase the effectiveness of whole program. Chaudhry and Ahmad (2001) describe the main elements of educational process as student, teacher, education, society, teaching and curriculum and the aspects of educational system as aims, content, teaching, assessment and evaluation. Assessment is defined as process of collection of facts by using variety of tools that is specifically for the purpose to check that how well students are meeting the expectations of curriculum. In the process of assessment teachers guide students by giving feedback in a descriptive way so that students observe their efforts for further development. The overall quality of assessment depends on worth of evaluation whereas evaluation is also described as a process which states the judgments and afterward decisions are made for interpreting data collected from assessment. Athanasou and Lamprianou (2002), added that assessment as a process of information collection for different tasks such as performance tests etc. This definition means you are free to 
include many different types of tasks (assignments, exercises, projects, quizzes etc.) under the umbrella of assessment. It also means that assessment is principally professional process of collation, comparison and judgment. Rowntree (1990) highlights two purposes of assessment while describing the concept of assessment: First, to provide response to students, and second upsurge their continuing knowledge, and also report what they had already achieved. These are called formative assessment and summative assessment respectively.

According to Morgan and O’Reilly (1999) assessment is the engine that drives and forms learning, rather than an end of course results that grades and reports on performance. So the process of assessment and evaluation should be based on the directions of the curriculum and the attainment levels proposed in the national curriculum. Actually the primary function of education is to enhance the cognitive, affective and psychomotor domains of the students' individual growth. It is defined in National Curriculum Framework (2006) that in an advanced, informative and technology-based culture needs critical thinkers, who have the ability of analysis and creativity. They should have the ability to resolve complications of several varieties on different levels and communicate their thoughts proficiently. A student gets training of knowledge, abilities and performances during study of mathematics which are vital for positive and valuable contribution in such society. With the development of technology, higher level of mathematical skill is essential.

Cockcroft (1982) emphasized to develop a connection between curriculum of mathematics and necessary skills for further education and employment. He proposed that mathematics should be taught in frameworks in which it would be used in practical life. He stressed for contextualization in the mathematics curriculum to improve the transfer of mathematical concepts taught in schools into useful skills. Cooper (1992) proposed that contextual assessment is not always appropriate. He recognized that when items included in paper are entrenched in 'real-life' contexts the learner is more likely to succeed if s/he equips with the knowledge of real life. This suggests that, although it may be more suitable to teach in meaningful contexts, in the assessment of mathematics learner may not benefit from questions which are mandatory for the mathematical structures, procedures, techniques facilitate learners with an agenda for rational thinking, mitigating assumptions and expressing ideas clearly. As students identify associations between daily circumstances and mathematical notions and establish linkage of mathematics with other subjects, actually serves to 
develop the skill for utilization of mathematics in daily practices and apply their knowledge in other arenas (Government of Pakistan, 2006).

The basic purpose of secondary education is to support predetermined educational objectives defined in the syllabus in terms to attain these objectives by the students and if so to what level. Schools, in our country, however, emphasized the development of scholastic traits i.e., the attainment of cognitive skills and knowledge. The focus of assessment system is to acquisition of cognitive outcomes, while ignoring the affective and psychomotor aspects of personality. The assessment is almost summative at the secondary level of education and the board examination stressed only the achievement of competence in academic areas. In a study conducted in Pakistani context on analysis of Pakistan Studies papers, Malik and Zaheer (2012) showed that these papers measure only the knowledge or understanding level of students. The abilities of students about how much they are able to apply that acquired knowledge are not assessed. Another study in international perspective by Reddy (2005), in which she analyzed the question papers to evaluate the instructional objectives, found that the questions formed in Mathematics question papers for years 2003 to 2005 assess ordinary mathematical skills, instead of complex cognitive abilities which have been defined in syllabus and in the curriculum outline. The research findings about analysis of mathematics questions papers are in international context. There is a need to study the problem in Pakistani scenario. This study is designed to analyze the question papers of Mathematics of BISE Lahore in the light of cognitive domain of Bloom's Taxonomy and quality of question papers. In a more descriptive way, the study is based on four objectives: 1) To analyze the questions papers in Mathematics in terms of levels of cognitive abilities; 2) To analyze the questions papers in terms of important parameters such as language clarity, suitability of marks allocation, construct and content validity etc.,; 3) To classify the weightage chosen in outline of assessment pattern prepared by the BISE; and 4) To determine the alignment of assessment scheme with respective papers.

\section{Conceptual and Theoretical Perspective}

The primary aim of education is the overall development of individuals aimed to bring about social changes in a desired way. The school as formal institution where education is conveyed and the educational objectives (desired outcomes) are sought to be managed through the educational programs. The school also assesses the execution 
of these objectives through examinations. Educational goals can redefine as to satisfy the basic learning requirements of learners in terms of learning tools and contents (Government of Pakistan 1998). Instructional objectives or the learning outcomes guide the entire process of education should be selected in such a way that the teacher could design appropriate instructional strategies to achieve them. There is a general agreement that the learning outcomes or the instructional objectives should be clear, achievable, and important. Naturally the educational objectives are broad. Bloom (1956) does not take educational objectives only as goals to design the curriculum or the direction in which instructions are guided but a source of thorough specification for building and application of evaluation techniques. According to taxonomy of educational objectives, learning domains are categorized into cognitive, psychomotor and affective. Objectives of cognitive domain are associated with values, ideas and information. They are also related to knowledge recollection and recognition and have strong bonds with developmental and logical skills which are linked with cognitive domain. Attitudes, behavior, and ideas are linked with affective domain whereas psychomotor domain connected with both motor mental activities of the students.

The objectives in the Cognitive Domain are drawn from famous Taxonomy of Educational objectives, namely Bloom's Taxonomy. Krathowl and Simpson (1966) worked on the Affective and Psychomotor Domains. These relate to the three primary domain of a pupil's learning: cognitive, affective and psychomotor. In order to promote higher forms of thinking Blooms taxonomy is considered foundational and vital. There are six major levels of cognitive abilities: knowledge, comprehension, application, analysis, synthesis and evaluation. Knowledge is the lowest and evaluation is the highest level of learning. The secondary level national curriculum for mathematics demands students' assessment of first four levels and consequently the textbook writers need to explain concepts that can promote students these levels.

National Education Policy 2009 suggests that to improve the innovative, self-activated, energetic and creative abilities in students, the education process should lead to create a balance attitude about human and nature; rise up their lifetime earnings along with adding collective and economic advancement of the nation and Ummah and support the Pakistan ideology in terms of societal, political and economic development at all levels of national and international forum. In order to promote students' higher abilities as described in National Education 
Policy 2009, assessment of students should be based on developing questions covering different cognitive levels.

The following characteristics highlight the National Curriculum for Mathematics: (a) the National curriculum is planned to support learners shape the solid theoretical foundation in Math that will assist them to apply their information proficiently and increase their knowledge effectively; (b) the curriculum expresses the geometrical ideas that help students to reflect rationally, reason analytically and estimate sensibly; (c) the emphasis of the curriculum for graphics is to facilitate learners to imagine and deduce mathematical terminologies correctly instead of manipulating 'blindly'; and (d) the curriculum identifies the benefits that existing technologies can convey to the learning and doing Mathematics. So it integrates the practices of appropriate technologies to develop knowledge in an ever increasingly information-rich world (Government of Pakistan, 2006).

National Curriculum for Mathematics (2006) expresses that teachers' part has been transmitted that moves from providing information' to designing tasks, handling a co-operative learning environment and managing students' creativity in increasing rational understanding of the theories of Mathematics. Specific procedures are planned for the development of student learning to confirm that assessment and evaluation are centered on curriculum expectations and the attainment levels enlisted in the curriculum. An effective learning-outcomesoriented excellence assurance structure that is grounded on continuous monitoring and purposeful feedback loops is suggested (Government of Pakistan, 2006).

\section{Significance of the Problem}

Development of question papers by subject teachers at institutional and Boards of Intermediate and Secondary Education (BISE) level is one of an important professional activity. In order to develop the question papers on scientific basis, the paper setters should have sound understanding and skill of designing Assessment Scheme/table of specification in accordance with the national curriculum. This study explores the analysis of question papers in regard to basic principles of test items construction and it determines how far the BISE question papers in the subject of mathematics are developed in accordance with Assessment Scheme. The researchers did not find adequate research on this problem and henceforth made an effort to highlight some of the 
strengths and weaknesses of the mathematics question papers developed by BISE in Punjab.

The study may beneficial for the teachers and teacher trainers for developing question papers to follow Assessment Scheme/Table of Specification, and basic principles of test item construction. It may provide feedback to the curriculum developers and textbook authors in regard to improve the quality of question papers in textbooks' exercises.

\section{Methodology}

Qualitative approach for this study was used as a methodology and it was based on the document analysis. The BISE paper setters in the subject of mathematics at grade IX and X level are instructed to design question papers according to the Assessment Scheme which is based on the national curriculum of mathematics (2006). They need to have had good background of Taxonomy of Educational Objectives.

Prior to analyzing question papers, the researchers thoroughly studied the national curriculum (2006) of mathematics and textbooks recommended by Punjab Textbook Board Lahore. They also studied in detail about the technical aspects of test items construction of objective and subjective types. The BISE Assessment Schemes of the available question papers in mathematics were also consulted. The readings of these documents enabled the researchers to do technical analysis of the past mathematics question papers.

The researchers selected BISE question papers of grade IX and X for the two years (2012 and 2013) for the analysis purpose. The question papers of the years 2012 and 2013 of secondary level were selected as sample for the analysis. The questions papers of class IX for the year 2013 were constructed following new syllabus, while question papers of the preceding year examinations were based on the old syllabus. These question papers were reviewed under categories of Bloom's Taxonomy. For analysis, firstly table of specifications were developed. Only one assessment scheme / table of specification was available by BISE for new syllabus 2013 and it was somehow used in developing question paper.

The question papers were reviewed based on two three parameters: 1) how far the basic principles of test construction were observed while developing mathematics question papers; 2) how far the question papers were aligned with BISE Assessment Scheme (wherever available); 
and 3) how far mathematics question papers of grade IX-X are free of typographical or grammatical errors.

\section{Results}

In the current study, the researcher examined every item of question paper of Mathematics against the different cognitive level of Bloom's Taxonomy. The researcher acquired two years question papers of Mathematics of BISE Lahore and measured characteristics of question papers. The assessment scheme developed by the Board specifies the distribution of the four objectives or ability levels - knowledge, comprehension, application and analysis; therefore the last two levels i.e. synthesis and evaluation was not considered.

\section{Analysis of Papers for Grade IX-X for the Year 2012}

The question papers of class IX-X for the year 2012 were critically reviewed and the following weightage of different cognitive abilities was found in these two papers.

Table 1

Weightage of Cognitive Levels of Bloom's Taxonomy in Question Papers of year 2012

\begin{tabular}{lcccc}
\hline & Knowledge & Comprehension & $\begin{array}{c}\text { Application } \\
\text { \& Analysis }\end{array}$ & Total \\
\hline Math-IX Paper 2012 & $34 \%$ & $48 \%$ & $18 \%$ & $100 \%$ \\
Weightage & 22 & 23 & 7 & 52 Items \\
No. of Items & $26 \%$ & $32 \%$ & $42 \%$ & $100 \%$ \\
Math-X Paper 2012 & 19 & 17 & 16 & 52 Items \\
Weightage & & & & \\
No. of Items & & &
\end{tabular}

Table 1shows that in the paper of Mathematics (2012) class IX, there were 22 items (34\%)of knowledge level, 23 items (48 \%) of comprehension level and 7 items (18\%) of application level of cognitive domain. This shows that the paper did not include the higher cognitive abilities of synthesis and evaluation. It establishes a great weightage for assessing the understanding level of students which may be considered as the average level of mental ability in Mathematics. In reviewing the question papers, greater emphasis on the chapter 5 and this was not in accordance with national curriculum. It was found that the weightage of 
chapter 5 and 6 was the same (13\%) in curriculum, but questions from chapter 5 were doubled than chapter 6, especially essay type. Grammatically wrong statement was found in a paper (Q.4. viii).It was found that question 3 was directly taken from solved examples of the textbook. It was also found that same question was constructed both in objective and subjective paper (MCQ 1.i and SAQs 4.viii). Hence there was replication of the same concept in two questions.The concept was given in short answer question (Q4) form as, What is meant by $A B$ ? While in MCQ (1.1) form it was asked as;
$\mathrm{AB}$ means: a) $\mathrm{m} \mathrm{AB}$
b) $\mathrm{AB}$
c) $\mathrm{AB} d) \mathrm{AB}$

\section{Analysis of Grade-X Math Paper 2012}

As regards Math paper (2012) for class X, Table 1shows that19 items (26\%) were of knowledge level, 17 items (32\%) of comprehension level and 16 items (42\%) of application level of cognitive domain. The weightage to content was found satisfactory except for a few chapters which were over stressed, such as Algebraic Sentences (chapter 1) and inadequate emphasis was placed on chapters like Information Handling (chapter 4) and Fundamental Concepts of Geometry (chapter 5).The weightage of chapter 1 was $18 \%$ and 35 marks were allotted to 17 questions. Whereas, the weightage of chapter 4 was $22 \%$ and only 09 marks were allotted to the questions and in chapter 5 the weightage was $10 \%$ and only 05 marks were allotted. In reviewing paper some questions had language errors (e.g. Q.4 \& 6).Questions were started with eliminating instead of eliminate. A basic drawback of the paper was that some questions were directly taken from worked examples in the textbook (Q.3 ii, Q.4 vii, Q.6 and Q.8). The finding revealed that that most of the objective and subjective questions covered the four cognitive abilities as mentioned in Assessment Scheme in the question paper of grade $\mathrm{X}$.

\section{Analysis of Papers for Grade IX-X for the Year 2013}

The question papers of class IX-X for the year 2013 were critically reviewed and the following weightage of different cognitive abilities was found in these two papers. 
Table 2

Weightage of Cognitive levels of Bloom's Taxonomy in Question paper of Math-IX (2013)

\begin{tabular}{lcccc}
\hline & Knowledge & Comprehension & $\begin{array}{c}\text { Application } \\
\& \text { Analysis }\end{array}$ & Total \\
\hline Weightage (BISE Pattern) & $42 \%$ & $41 \%$ & $17 \%$ & $100 \%$ \\
No of Items & 21 & 20 & 11 & 52 Items \\
Weightage (Amended after Revision) & $36 \%$ & $36 \%$ & $28 \%$ & $100 \%$ \\
No of Items & 23 & 18 & 11 & 52 Items \\
\hline
\end{tabular}

New syllabus 2013 according to National Curriculum (2006)

The 2013 paper of class IX was developed on a new syllabus and assessment scheme, which involves on developing the lower level of mathematical abilities. Assessment scheme shows less emphasis on application and analysis level of cognitive abilities. (Annexure A). The table of specification was amended after analysis of question paper within alignment with assessment scheme. The table shows the change in figures. Items related to knowledge level were changed from $42 \%$ to $36 \%$, understanding level from $41 \%$ to $36 \%$, application and analysis level from $17 \%$ to $28 \%$.

\section{Analysis of Grade-IX Math Paper 2013}

Table 2 shows that in the paper of Mathematics (2013) class IX, 21 items (42\%) of knowledge level, 19 items (41\%) of comprehension level and 11 items (17\%)of application and analysis level of cognitive domain. Many deficiencies were found in comparison of table of specification (TOS) and in construction of paper. It is found that there were 4 MCQs in TOS as application type items. Only one MCQ was valid, rest of three were from knowledge category. (Part I: vi, viii, x, xii).i.e. 1.6) ----ratios are defined as proportion of equality.
a) 2
b) 3
c) 4
d) 5

1.8) The right bisectors of the sides of triangle are:
a) con current
b) non concurrent
c) parallel
d) non parallel

1.10) Line $A B$ is represented as:
a) $\overrightarrow{\mathrm{AB}}$
b) $\mathrm{AB}$
c) $\overleftarrow{\mathrm{AB}}$
d) $\stackrel{\mathrm{AB}}{\longrightarrow}$ 
All these three MCQs show the nature of knowledge category rather than application category. In essay type questions only one item of application level was mentioned in TOS, whereas five questions of application and analysis were found (Q.7, 8.a, 8.b, 9.a, 9.b). It was also found that same question was constructed both in objective and subjective paper.(MCQ 1.viii and ETQ 9.a). The worse thing which was found that MCQ was categorized as application level and ETQ was categorized as knowledge level in table of specification.Q.2. vii, ix were directly taken from the solved examples in the textbook, which was not a healthy trend and should be avoided. A very serious mistake was found in the paper in Q.8.b. The statement was not matched with the values given i.e. Construct triangle $\mathrm{XYZ}$, where

$\mathrm{m} \angle \mathrm{B}=45 \mathrm{O}, \mathrm{m} \angle \mathrm{A}=750, \mathrm{~m} \overline{\mathrm{AB}}=3.6 \mathrm{~cm}$.It was found that 23 out of the 52 questions in the paper were constructed from geometry portion.

\section{Analysis of Math-X Paper 2013}

In the paper of Mathematics (2013) class X, there were17 items (25\%) of knowledge level, 20 items (34\%) of comprehension level and 15 items (41\%)of application level of cognitive domain. Compared to class IX-2013 paper, the situation seems to worse in geometry, with questions regarding geometry were totally absent in essay type part, whereas in IX papers too much emphases was found. The analysis of the paper regarding the weightage portrays similar trend to that in the $2012 \mathrm{X}$ paper. Greater emphasis on the chapter 1 was found. The weightage of chapter 1 was $18 \%$ and 32 marks were allotted to 17 questions. In short questions 33\% questions from chapter 1 was included. It was also found that chapter 5 neglected in essay type part, this belonged to geometry concepts. It was found that marks distribution of chapter 5 was less and needed to be improved.

Table No. 3

Cumulative Results of Question papers of Mathematics

\begin{tabular}{lcccc}
\hline Year & Knowledge & Comprehension & $\begin{array}{c}\text { Application } \\
\text { \& Analysis }\end{array}$ & Total \\
\hline IX 2012 & $34 \%$ & $48 \%$ & $18 \%$ & $100 \%$ \\
IX 2013 (BISE Pattern) & $42 \%$ & $41 \%$ & $17 \%$ & $100 \%$ \\
IX 2013 (Amended) & $36 \%$ & $36 \%$ & $28 \%$ & $100 \%$ \\
X 2012 & $26 \%$ & $32 \%$ & $42 \%$ & $100 \%$ \\
X 2013 & $25 \%$ & $34 \%$ & $41 \%$ & $100 \%$ \\
\hline
\end{tabular}


Table 3 shows cumulative results of all question papers from (20122013). It shows differences between weightage of cognitive levels of class IX and X papers. Class IX question papers are mostly assessing lower level of cognitive abilities as knowledge and comprehension level and little stress on higher level abilities. Whereas class $\mathrm{X}$ papers shows the satisfactory level of different cognitive level abilities.

The analysis of two years (2012-2013) question papers has assessed questions on important parameters relating to the overall quality of the questions. The major shortcomings in the papers as a whole were that the questions given from examples especially in grade IX paper of the year 2013. In multiple choice questions (MCQs), alternatives of the stem are not written vertically and not presented in alphabetical order. There was also the problem of plausibility among options in many of the MCQs.

In developing the questions, the language should be simple and clear-cut, and this characteristic of a good question was used by all questions given in the Mathematics paper. They were simply expressed and could be easily understood. Almost all questions were appropriate for testing the specific objective. All questions were selected from the given content; almost all sampled the same area of content they attempted to inspect. All questions were stated positively. Appropriate marks and suitable time were allotted to all categories. Proper directional words were found to be used for majority of the questions. Therefore, it can be stated that in all the two years Mathematics papers, while number of questions fulfilled the other criteria which are significant for them to be categorized as good questions. The paper 2013-X paper displayed overall a good paper in comparison with others.

\section{Conclusion and Recommendations}

The study reveals that the papers of Mathematics IX (2012-2013) have much emphasis on the cognitive abilities of knowledge and comprehensive, whereas higher order questions are either ignored or given a little weightage. Students know basics but they don't have capability to apply all these knowledge in different situations. Their ability to analyse problems and create new ideas is not assessed. The general view of all the papers is that the questions assessing the application ability have to be increased while those assessing comprehensive ability have to be reduced. This would then make the paper more balanced and in accordance with the assessment scheme. While analysing assessment scheme 2013 of class IX 
constructed by BISE, it seems that there is no coordination between the papermakers and assessment scheme makers.

Papers of class X of the years 2012-2013 tend to be of the average level in terms of the difficulty level. Compared to class IX papers, in X2012, the situation seems to worse in geometry, with questions assessing the abilities regarding geometry are totally absent in essay type part, whereas in IX papers too much emphases is found. In X-2013 paper, satisfactory distribution of weightage for assessing the knowledge, understanding, application and analysis objectives are found. In comparison with all papers, class X-paper 2013 displays overall a satisfactory paper.

After analysing the Mathematics papers, the findings and conclusions indicate some important recommendations which can be put forwarded to improve the quality of question papers in the subject of mathematics at secondary level.

1. At present, papers of BISE in the subject of Mathematics for class IX measure mostly students' knowledge and comprehension abilities. There is need to revise assessment practices of BISE, by giving more emphasis on higher cognitive abilities.

2. Teachers need to practice developing question papers based on Bloom's taxonomy in accordance with the basic rules of test item construction in Mathematics.

3. BISE may allocate only expert teachers in mathematics for paper setting who are familiar thoroughly with teaching learning process and well aware of assessment procedures and approaches.

4. BISE should consistently train paper setters in developing quality question papers that can truly measure various cognitive abilities of students.

5. After composing, the papers should be rechecked thoroughly by the experts before printing in terms typographical / grammatical errors.

6. The Research Wing of each BISE should be made functional by appointing only psychometricians.

7. BISE may provide access to all teachers of the Assessment Scheme/Table of Specification in mathematics so as to ensure content validity in the papers in accordance with national curriculum and textbooks. 


\section{References}

Athanasou, J. \& Lamprianou, I. (2005). A Teachers Guide to Assessment. Southbank Victoria, Australia: Thomson Social Science Press.

Bloom B. S. (1956). The cognitive domain: Taxonomy of educational objectives handbook I. New York: David McKay Co Inc.

Chaudhry, A.S. \& Ahmad, M. (2001) Rehber-Ilm-ul-Taleem. Lahore, Pakistan: Qureshi Brothers’ Publishers.

Cockcroft, W.H. (1982). Mathematics counts: Report of the committee of inquiry teachings of mathematics in schools. London: Her Majesty's Stationery Office.

Cooper, B. (1992). Testing national curriculum mathematics: Some critical comments on the treatment of 'real' contexts in mathematics. The Curriculum Journal, 3, 231-243.

Government of Pakistan (2006). National curriculum for mathematics 2006. Islamabad: Federal Ministry of Education.

Government of Pakistan (1998). National education policy 1998-2010. Islamabad: Federal Ministry of Education.

Malik, S. \& Zaheer, I. (2012). An Analysis of Pakistan Studies Question Papers at Secondary Level. Interdisciplinary Journal of Contemporary Research Business, 4(5), 340- 365.

Morgan, C. \& O’Reilly, M. (1999). Assessing open and distance learners. Sterling, VA: Stylus Publishing.

Rowntree, D. (1990) Teaching through self-instruction $\left(2^{\text {nd }}\right.$ ed.), London: Kogan Page. 


\section{Web Sources}

http://www.azimpremjifoundation.org/pdf/SecondaryExamsTotalreport.p df (accessed on 10/03/2014).

http://www.hec.gov.pk/InsideHEC/Division/LearningInnovations/Docu ments/Curriculum/

Development/Assessment (accessed on 25/02/2014).

http://www.ibe.unesco.org/curricula/pakistan/pk_al_mt_2006_eng.pdf (accessed on 24/12/2013).

http://www.pec.edu.pk (accessed on 24/12/2013) 


\section{Annexure A}

\section{Table of Specification Class IX 2013}

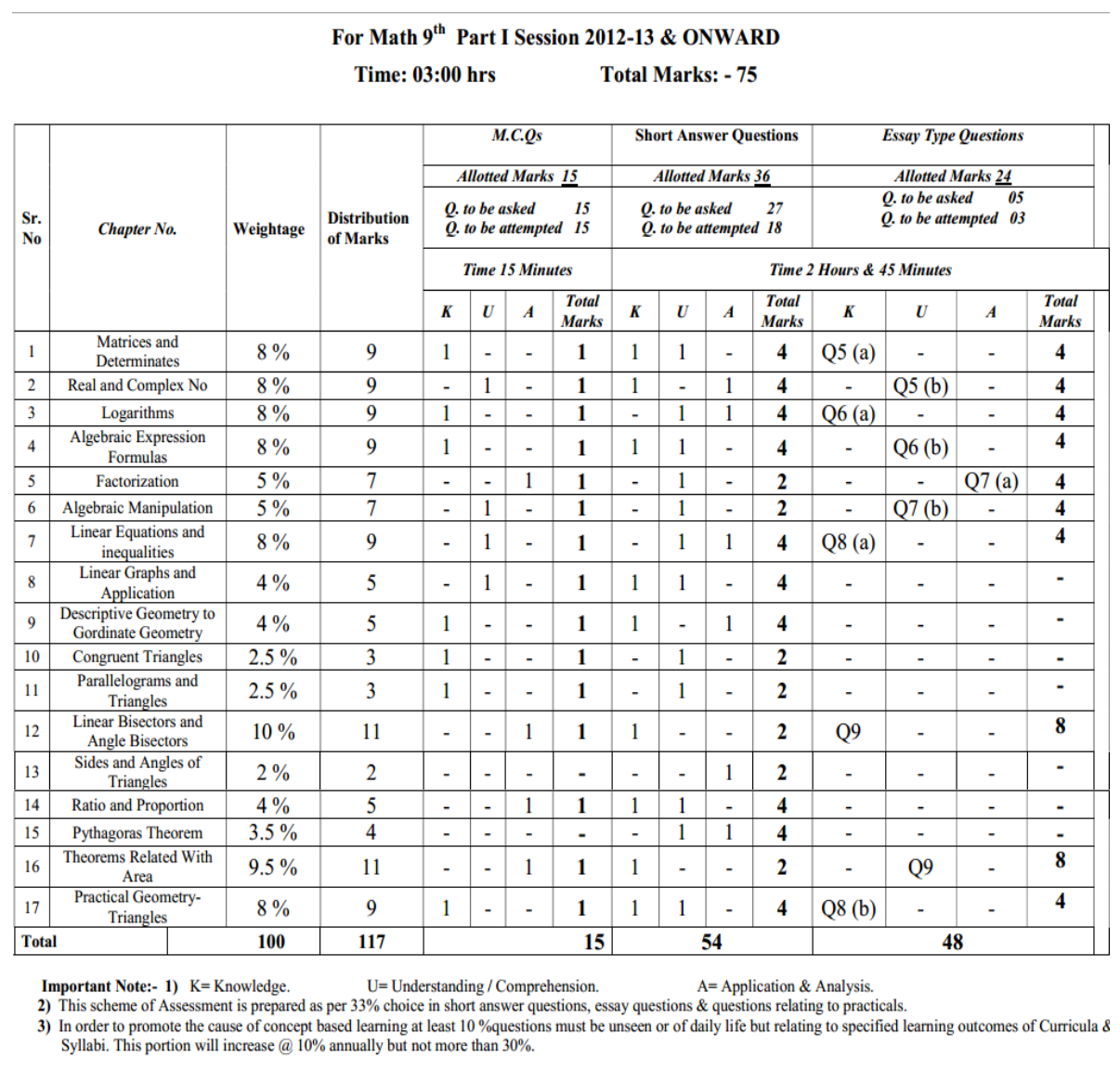

Received on: February 2, 2016

Revised on: April 13, 2016

Accepted on: June 04, 2016 